\title{
ROLE OF HOST AND TEMPERATURE ON THE FEEDING AND OVIPOSITION BEHAVIOUR OF RED PUMPKIN BEETLE Aulacophora foveicollis (LUCAS)
}

\author{
M. M. Kamal' ${ }^{1}$, M. M. Uddin, M. Shajahan and M. M. Rahman \\ Department of Entomology, Bangladesh Agricultural University \\ Mymensingh-2202, Bangladesh
}

\begin{abstract}
The research was carried out in the field and laboratory of the Department of Entomology, Bangladesh Agricultural University, Mymensingh during December, 2011 to October, 2012 on the effect of host and temperature on oviposition and food consumption of red pumpkin beetle (RPB), Aulacophora foveicollis (Lucas). Three cucurbitaceous vegetables viz. sweet gourd (BARI Misti Kumra-1, BARI Misti Kumra-2 and Local Misti Kumra), bitter gourd (BARI Karola-1, Taj Karola-88 and Local Karola) and bottle gourd (BARI Lau-3, BARI Lau -4 and Local Lau) were selected to conduct this research. Host plants had the clear role on the feeding of red pumpkin beetle. Due to feeding of A. foveicollis, the highest percentage of weight loss of leaf was recorded from sweet gourd among the selected cucurbits while Local Misti Kumra was found the most preferred host by beetle considering their feeding efficacy compared to other varieties. Results also showed that temperature had a profound effect on the oviposition and food consumption by $A$. foveicollis while $30^{\circ} \mathrm{C}$ was the optimum temperature both for oviposition and food consumption for all selected cucurbits and their varieties.
\end{abstract}

Key Words: Role, Host, Temperature, Feeding, Oviposition, Behaviour, Red pumpkin beetle

\section{INTRODUCTION}

Cucurbits are one of the most important vegetables in Bangladesh principally cultivated in summer season during the scarcity of other vegetables. Cucurbits form the largest group of vegetables where the bottle gourd, sweet gourd, bitter gourd, ridged gourd, sponge gourd, teasel gourd, white gourd, ash gourd, cucumber are cultivated as major vegetable in Bangladesh. Cucurbits have a good nutritive value as well as medicinal value. All the cucurbits have a good market value which encourages the farmer to cultivate gourds in large scale. The total area of cucurbit crops is around 81,720 hectares and the total production is about 3,08,096 tons (CRDS, 2010). Although cucurbits are summer crop but some of them can be grown throughout the year because of their photo insensitiveness. The climate of Bangladesh is favourable for growing most of the vegetable crops specially cucurbits.

\footnotetext{
${ }^{1}$ MS Student, 2 Professor and ${ }^{3}$ Asistant Professor, Department of Entomology, Bangladesh Agricultural University, Mymensingh-2202, Bangladesh

*Corresponding author (Email: mahirbau@yahoo.com)
} 
Cucurbit production is severely affected by a number of insect pests such as red pumpkin beetle, cucurbit fruit fly, epilachna beetle etc. Among them red pumpkin beetle, Aulacophora foveicollis (Lucas) is one of the major constraint to its production capable of $30-100 \%$ yield loss (Alam, 1969; Gupta and Verna, 1992 and Dillon et al., 2005) especially at seedling stage (Rajak, 2001). It is polyphagous in nature and attacks more than 81 plant species including bottle gourd, sweet gourd, bitter gourd, ridged gourd, sponge gourd, teasel gourd, white gourd, ash gourd, cucumber, squash, water melon, etc. and a wide range of fruit crops (Doharey, 1983). In Bangladesh, red pumpkin beetle, A. foveicollis causes severe damage of cucurbitaceous vegetables (Alam, 1969; Azim, 1966 and Butani and Jotwani, 1984).

This pest is widely distributed all over the South-East Asia as well as the Mediterranean region towards the West and Australia in the East (Butani et al., 1984). The adult beetle is red, oblong and approximately 6-8 $\mathrm{mm}$ long and lays its eggs at the base of the cucumber stem. After hatching young grub feed on roots, underground stem, stem and fruits touching to the soil as a result plant become wilted causing direct damage to the newly developed seedlings (Narayanan, 1960). The adult beetles feed voraciously on the leaf lamina making irregular holes (Butani and Jotwani, 1984). They also attack anthers, pollen, stigma and ovary rendering the flowers incapable of fruiting. The beetles also injure fruits, producing characteristic circular bands of injury which help in rotting and subsequent attack of diseases of the fruits. The pest, however, occurs throughout the year and causes severe damage to the crops especially at seedling stage (Rajak, 2001).

The severity as well of extent of damage is dependent on biotic and abiotic factors such as host preference, oviposition behavior, nature of food consumption, environmental conditions etc. According to Gupta and Verma, 1992 and Dhillon et al., 2005, depending on the environmental conditions and susceptibility of the crop species, the extent of damage by red pumpkin beetle varies between 30 to $100 \%$. To manage this serious pest it is necessary to study the effect of host and temperature on the feeding and oviposition of red pumpkin beetle. But information on this topic is scanty. Therefore, the current study was planned to investigate on the red pumpkin beetle with the following objectives:

i. to measure the food consumption of the beetle among different crops and varieties of cucurbits in the laboratory

ii. to investigate the effect of temperature on the feeding and oviposition of the adult beetle

\section{MATERIALS AND METHODS}

Experiments were conducted in the laboratory of the Department of Entomology, Bangladesh Agricultural University (BAU), Mymensingh during December, 2011 to October, 2012. The test plants of three cucurbitaceous vegetables such as sweet gourd (BARI Misti Kumra-1, BARI Misti Kumra-2 and Local Misti Kumra), bitter gourd (BARI Karola-1, Taj Karola-88 and Local Karola) and bottle gourd (BARI Lau-3, BARI Lau -4 and Local Lau) were grown in the field laboratory, Department of Entomology with maintaining all recommended agronomic practices to conduct the research work for which the quality seeds were collected from Bangladesh Agricultural Research Institute (BARI), Gazipur and seed stores of Mymensingh town. 
To estimate the food consumption, two adult beetles were released in each petri dish containing a leaf each of nine varieties. Three petri dishes were maintained for each variety. Fresh leaves of plants were supplied daily. The cut end of leaf petiole was provided with water soaked cotton pad to prevent withering of leaf. Food consumption was determined by measuring the weight loss of consumed leaf by the beetle using an electric balance. This experiment was carried out up to seven days. Weight loss of leaf was calculated as percentage. Percentage weight loss was calculated by deducting the \% weight loss of fresh leaf from the eaten leaf by the beetle. Pooled means for three crops calculated from the mean values of three varieties of each crop.

To study the influence of temperature on the food consumption and oviposition of the beetle, experiments were conducted at three distinct temperatures viz. $15^{\circ} \mathrm{C}, 25^{\circ} \mathrm{C}$ and $30^{\circ} \mathrm{C}$ on three nine varieties of cucurbitaceous vegetables with three replications for each in the laboratory using an incubator. Two adult red pumpkin beetles (male + female) were released in each Petri- dish with leaves as food and then these petri dishes were put inside the incubator. The experiment was replicated three times. The quantity $\left(\mathrm{mm}^{2}\right)$ of food consumed by adult beetles per day was measured using square millimeter graph paper simultaneously the number of eggs laid on each variety was counted.

Data obtained from different experiments were analyzed using a statistical package program MSTAT-C and the mean values were ranked by Duncan's Multiple Range Test (DMRT).

\section{RESULTS AND DISCUSSION}

\section{Role of different hosts on food consumption of red pumpkin beetle Role of different crops}

Food consumption of red pumpkin beetle varied significantly on leaves of different cucurbit crops (Table 1). Due to feeding of red pumpkin beetle the highest percentage of weight loss was recorded on sweet gourd (13.68\%) and the lowest was recorded on bitter gourd (3.14\%) where the moderate weight loss was recorded on bottle gourd $(7.97 \%)$. Percentage weight lost due to beetle feeding indicated that host plants had some effect on the food consumption of red pumpkin beetle.

\section{Role of different varieties}

Percentage weight loss of leaves due to the feeding of red pumpkin beetle on nine selected varieties showed that the highest percentage of weight loss was on Local Misti Kumra (15.34\%) followed by BARI Misti Kumra-1 (12.92\%) and BARI Misti Kumra-2 (12.78\%) whereas the lowest percentages of weight loss was (2.85\%) on BARI Karola-1 followed by Local Karola $(2.95 \%)$ and Taj Karola-88 $(3.62 \%)$ due to feeding of red pumpkin beetle (Table 2). Therefore, it can be concluded that cucurbit varieties influenced the food consumption of red pumpkin beetle. 
Table 1. Percentage of weight loss of leaf among three cucurbit crops in laboratory

\begin{tabular}{l|c}
\hline \multicolumn{1}{c|}{ Crop } & Percentage weight loss of leaf day-1 \\
\hline Sweet gourd & $13.68^{\mathrm{a}}$ \\
Bitter gourd & $3.14^{\mathrm{c}}$ \\
Bottle gourd & $7.97 \mathrm{~b}$ \\
Mean & 8.26 \\
\pm SE & 3.04 \\
LSD value & 2.07 \\
Level of significance & 0.01 \\
\hline CV $(\%)$ & 10.67 \\
\hline
\end{tabular}

Means followed by common letters are not significantly different

Table 2. Percentage of weight loss of leaf among nine cucurbit varieties in laboratory

\begin{tabular}{ll|c}
\hline \multicolumn{1}{c}{ Crop } & \multicolumn{1}{c}{ Variety } & Percentage of weight loss of leaf day-1 \\
\hline \multirow{3}{*}{ Sweet gourd } & BARI Misti Kumra-1 & $12.2^{\mathrm{b}}$ \\
& BARI Misti Kumra-2 & $12.78^{\mathrm{b}}$ \\
& Local Misti Kumra & $15.34^{\mathrm{a}}$ \\
& BARI Karola-1 & $2.85^{\mathrm{d}}$ \\
Bitter gourd & Taj Karola-88 & $3.62^{\mathrm{d}}$ \\
& Local Karola & $2.95^{\mathrm{d}}$ \\
& BARI Lau-3 & $8.45^{\mathrm{c}}$ \\
Bottle gourd & BARI Lau-4 & $7.62^{\mathrm{c}}$ \\
& Local Lau & $7.85^{\mathrm{c}}$ \\
\hline Mean & & 8.27 \\
\hline \pm SE & & 1.54 \\
\hline LSD value & & 1.51 \\
\hline Level of significance & 0.05 \\
\hline CV $(\%)$ & 10.67 \\
\hline
\end{tabular}

Means followed by common letters are not significantly different

Present findings reveal that the daily food consumption of red pumpkin beetle was highly influenced by the hosts. Therefore, it can be concluded that both the crops and varieties have profound role on the food consumption of red pumpkin beetle. This result was in agreement with the observation with Hasan et al., 2012; Khan et al., 2011 and Rajak, 2001 but differed from the finding of Begum, 2002.

\section{Effect of temperature on oviposistion of red pumpkin beetle}

\section{Among different crops}

The egg laying performance on three cucurbits at different controlled temperatures varied significantly. The maximum number of egg was laid at $30^{\circ} \mathrm{C}$ temperature followed by $25^{\circ} \mathrm{C}$ and the lowest at $15^{\circ} \mathrm{C}$ (Table 3 ). At $30^{\circ} \mathrm{C}$ temperature, the maximum number of egg was 
laid on the sweet gourd (19.89) followed by bottle gourd (14.78) and minimum egg was laid on the bitter gourd (8.89). At $25^{\circ} \mathrm{C}$ temperature, no egg was laid on bitter gourd whereas the highest number of eggs (17.0) was laid on sweet gourd followed by bottle gourd (11.11). At $15^{\circ} \mathrm{C}$ temperature, no egg was laid on bitter gourd by RPB and the highest (9.78) was found on sweet gourd followed by bottle gourd (7.67). Among three temperature $30^{\circ} \mathrm{C}$ was the optimum for the beetle oviposition where they laid maximum number of eggs.

Table 3. Effect of temperature on oviposition in incubator among three cucurbit crops

\begin{tabular}{|c|c|c|c|}
\hline \multirow[t]{2}{*}{ Crop } & \multicolumn{3}{|c|}{ No. of eggs laid per day at different temperature } \\
\hline & $15^{\circ} \mathrm{C}$ & $25^{\circ} \mathrm{C}$ & $30^{\circ} \mathrm{C}$ \\
\hline Sweet gourd & $9.78^{\mathrm{a}}$ & $17.00^{\mathrm{a}}$ & $19.89 \mathrm{a}$ \\
\hline Bitter gourd & $0.00 c$ & $0.00^{c}$ & $8.89 c$ \\
\hline Bottle gourd & $7.67 \mathrm{~b}$ & $11.11^{\mathrm{b}}$ & $14.78^{\mathrm{b}}$ \\
\hline Mean & 5.81 & 9.37 & 14.51 \\
\hline$\pm \mathrm{SE}$ & 2.97 & 4.98 & 3.18 \\
\hline LSD value & 2.02 & 2.63 & 3.56 \\
\hline Level of significance & 0.01 & 0.01 & 0.01 \\
\hline $\mathrm{CV}(\%)$ & 14.80 & 11.98 & 10.44 \\
\hline
\end{tabular}

Means followed by common letters are not significantly different

\section{Among different varieties}

At $15^{\circ} \mathrm{C}$ in incubator, among nine varieties the highest egg was laid on BARI Misti Kumra1(10.67) followed by BARI Misti Kumra-2 (10.00) and Local Misti Kumra and Local Lau (8.67) which were statistically identical (Table 4). The lowest number of egg was laid on BARI Lau-4 (6.67) followed by BARI Lau-3 (7.67). No egg was laid on three bitter gourd varieties. At $25^{\circ} \mathrm{C}$ in incubator, the highest egg was found on Local Misti Kumra (20.67) followed by BARI Misti Kumra-2 (15.67) and BARI Misti Kumra-1 (14.67). The lowest number of egg was laid on BARI Lau-4 (10.33) followed by BARI Lau-3(11.00) and local Lau (12.00). No egg was found on three bitter gourd varieties at $25^{\circ} \mathrm{C}$ temperature. At $30^{\circ} \mathrm{C}$ in incubator, the highest egg was laid on Local Misti Kumra (23.67) followed by BARI Misti Kumra-2 (18.67) and BARI Misti Kumra-1 (17.33). The lowest number of egg was laid on Local Karola (8.00) followed by Taj Karola-88 (8.33) and BARI Karola-1 (10.33). Among three temperatures $30^{\circ} \mathrm{C}$ was found optimum for the beetle oviposition. This result agrees with the result of Das et al. (2012) where they stated that temperature had effect on the oviposition of epilachna beetle among different brinjal varieties.

\section{Effect of temperature on food consumption of red pumpkin beetle}

\section{Among different crops}

At 15,25 and $30^{\circ} \mathrm{C}$ temperature the highest daily food consumption was recorded on sweet gourd which were $21.03 \mathrm{~mm}^{2}, 35.74 \mathrm{~mm}^{2}$ and $52.84 \mathrm{~mm}^{2}$ followed by bottle gourd on which 
food consumptions were $14.35 \mathrm{~mm}^{2}, 17.55 \mathrm{~mm}^{2}$ and $21.64 \mathrm{~mm}^{2}$, respectively whereas the lowest food consumption per day at 15,25 and $30^{\circ} \mathrm{C}$ temperature recorded on bitter gourd were $4.02 \mathrm{~mm}^{2}, 4.61 \mathrm{~mm} 2$ and $5.67 \mathrm{~mm}^{2}$. The food consumption differed significantly among three cucurbit crops (Table 5). It was noticed that $30^{\circ} \mathrm{C}$ temperatures was congenial for food consumption by adult beetles.

Table 4. Effect of temperature on oviposition in incubator among nine cucurbit varieties

\begin{tabular}{|c|c|c|c|c|}
\hline \multirow[t]{2}{*}{ Crop } & \multirow[t]{2}{*}{ Variety } & \multicolumn{3}{|c|}{ No. of eggs laid per day at different temperature } \\
\hline & & $15^{\circ} \mathrm{C}$ & $25^{\circ} \mathrm{C}$ & $30^{\circ} \mathrm{C}$ \\
\hline \multirow[t]{3}{*}{ Sweet gourd } & BARI Misti Kumra-1 & $10.67 \mathrm{a}$ & $14.67 \mathrm{~b}$ & $17.33^{b c}$ \\
\hline & BARI Misti Kumra-2 & $10.00^{\mathrm{ab}}$ & $15.67 \mathrm{~b}$ & $18.67 \mathrm{~b}$ \\
\hline & Local Misti Kumra & $8.67 \mathrm{bc}$ & $20.67 \mathrm{a}$ & $23.67 \mathrm{a}$ \\
\hline \multirow[t]{3}{*}{ Bitter gourd } & BARI Karola-1 & 0.00 e & $0.00^{\mathrm{d}}$ & 10.33 de \\
\hline & Taj Karola-88 & $0.00 \mathrm{e}$ & $0.00 \mathrm{~d}$ & $8.33^{\mathrm{e}}$ \\
\hline & Local Karola & $0.00 \mathrm{e}$ & $0.00^{\mathrm{d}}$ & $8.00 \mathrm{e}$ \\
\hline \multirow[t]{3}{*}{ Bottle gourd } & BARI Lau-3 & $7.67 \mathrm{~cd}$ & $11.00^{c}$ & $14.33^{c}$ \\
\hline & BARI Lau-4 & $6.67 \mathrm{~d}$ & $10.33^{c}$ & $13.67 \mathrm{~cd}$ \\
\hline & Local Lau & $8.67 \mathrm{bc}$ & $12.00^{c}$ & $16.33^{b c}$ \\
\hline \multicolumn{2}{|l|}{ Mean } & 5.82 & 9.370 & 14.51 \\
\hline \multicolumn{2}{|l|}{$\pm \mathrm{SE}$} & 1.50 & 2.55 & 1.71 \\
\hline \multicolumn{2}{|l|}{ LSD value } & 1.47 & 2.637 & 3.561 \\
\hline \multicolumn{2}{|c|}{ Level of significance } & 0.05 & 0.01 & 0.01 \\
\hline \multicolumn{2}{|l|}{$\mathrm{CV}(\%)$} & 14.80 & 11.98 & 10.44 \\
\hline
\end{tabular}

Means followed by common letters are not significantly different

Table 5. Effect of temperature on adult food consumption $\left(\mathrm{mm}^{2}\right)$ in incubator among three cucurbit crops

\begin{tabular}{l|c|c|c}
\hline \multirow{2}{*}{ Crop } & \multicolumn{3}{c}{ Daily adult food consumption at different temperature $\left(\mathbf{m m}^{2}\right)$} \\
\cline { 2 - 4 } & $\mathbf{1 5}^{\mathbf{0}} \mathbf{C}$ & $\mathbf{2 5}^{\mathbf{0}} \mathbf{C}$ & $\mathbf{3 0 ^ { \circ } \mathbf { C }}$ \\
\hline Sweet gourd & $21.03^{\mathrm{a}}$ & $35.74^{\mathrm{a}}$ & $52.84^{\mathrm{a}}$ \\
Bitter gourd & $4.02^{\mathrm{c}}$ & $4.61^{\mathrm{c}}$ & $5.67 \mathrm{c}$ \\
Bottle gourd & $14.35^{\mathrm{b}}$ & $17.55^{\mathrm{b}}$ & $21.64^{\mathrm{b}}$ \\
\hline Mean & 13.13 & 19.29 & 26.71 \\
\hline \pm SE & 4.95 & 9.03 & 13.85 \\
\hline LSD value & 4.38 & 4.26 & 6.22 \\
\hline Level of significance & 0.01 & 0.01 & 0.01 \\
\hline CV $(\%)$ & 14.21 & 9.39 & 9.92 \\
\hline
\end{tabular}

Means followed by common letters are not significantly different

\section{Among different varieties}

Daily food consumption of RPB differed significantly at various temperature among nine varieties of cucurbits (Table 6). At $15^{\circ} \mathrm{C}$ temperature among nine varieties of cucurbit the 
highest daily food consumption was recorded on Local Misti Kumra $\left(28.42 \mathrm{~mm}^{2}\right)$ followed by BARI Misti Kumra-2 $\left(18.56 \mathrm{~mm}^{2}\right)$ and BARI Misti Kumra-1 $\left(16.11 \mathrm{~mm}^{2}\right)$. The lowest food consumption by RPB was observed on the leaf of Taj Karola-88 $\left(2.83 \mathrm{~mm}^{2}\right)$ followed by BARI Karola-1 $\left(3.42 \mathrm{~mm}^{2}\right)$ and local Karola $\left(5.80 \mathrm{~mm}^{2}\right)$. The highest daily food consumption by RPB at $25{ }^{\circ} \mathrm{C}$ in incubator was obseved on the leaf of Local Misti Kumra $\left(40.70 \mathrm{~mm}^{2}\right)$ followed by BARI Misti Kumra-1 (33.99 mm²) and BARI Misti Kumra-2 $\left(32.52 \mathrm{~mm}^{2}\right)$. The lowest food consumption by RPB in incubator was observed on the leaf of Taj Karola-88 $\left(3.00 \mathrm{~mm}^{2}\right)$ followed by BARI Karola- $1\left(4.92 \mathrm{~mm}^{2}\right)$ and Local Karola $\left(5.89 \mathrm{~mm}^{2}\right)$. The highest daily food consumption by RPB at $30{ }^{\circ} \mathrm{C}$ in incubator was obseved on the leaf of Local Misti Kumra $\left(65.90 \mathrm{~mm}^{2}\right)$ followed by BARI Misti Kumra-1 $\left(47.69 \mathrm{~mm}^{2}\right)$ and BARI Misti Kumra-2 $\left(44.93 \mathrm{~mm}^{2}\right)$. The lowest food consumption was observed on the leaf of Taj Karola-88 (3.42 $\left.\mathrm{mm}^{2}\right)$ followed by Local Karola $\left(6.42 \mathrm{~mm}^{2}\right)$. It was noticed that $30^{\circ} \mathrm{C}$ temperature was congenial for food consumption of adult beetles whereas 15 and $25^{\circ} \mathrm{C}$ temperature were not as favorable as $30^{\circ} \mathrm{C}$ temperature but insects were able to survive through feeding. This result was in agreement with the observation with Chaudry and Alikhan, 1990.

Table 6. Effect of temperature on adult food consumption $\left(\mathrm{mm}^{2}\right)$ in incubator among nine varieties

\begin{tabular}{|c|c|c|c|c|}
\hline \multirow[t]{2}{*}{ Crop } & \multirow[t]{2}{*}{ Variety } & \multicolumn{3}{|c|}{$\begin{array}{l}\text { Daily adult food consumption at different } \\
\text { temperature }\left(\mathrm{mm}^{2}\right)\end{array}$} \\
\hline & & $15^{\circ} \mathrm{C}$ & $25^{\circ} \mathrm{C}$ & $30^{\circ} \mathrm{C}$ \\
\hline \multirow{3}{*}{ Sweet gourd } & BARI Misti Kumra-1 & $16.11^{b}$ & $33.99 \mathrm{~b}$ & $47.69 \mathrm{~b}$ \\
\hline & BARI Misti Kumra-2 & $18.56^{b}$ & $32.52^{b}$ & $44.93 \mathrm{~b}$ \\
\hline & Local Misti Kumra & $28.42^{a}$ & $40.70^{a}$ & $65.90^{a}$ \\
\hline \multirow{3}{*}{ Bitter gourd } & BARI Karola-1 & $3.42^{\mathrm{d}}$ & $4.92 \mathrm{e}$ & $7.17 \mathrm{e}$ \\
\hline & Taj Karola-88 & $2.83^{\mathrm{d}}$ & $3.00 \mathrm{e}$ & $3.42^{\mathrm{e}}$ \\
\hline & Local Karola & $5.80^{\mathrm{d}}$ & $5.89 \mathrm{e}$ & $6.42 \mathrm{e}$ \\
\hline \multirow{3}{*}{ Bottle gourd } & BARI Lau-3 & $17.21^{b}$ & $20.75^{c}$ & $27.17 \mathrm{c}$ \\
\hline & BARI Lau-4 & $10.41^{c}$ & $13.41^{\mathrm{d}}$ & $16.67 \mathrm{~d}$ \\
\hline & Local Lau & $15.42^{b}$ & $18.48^{\mathrm{c}}$ & $21.08^{\mathrm{cd}}$ \\
\hline Mean & & 13.13 & 19.29 & 26.71 \\
\hline$\pm \mathrm{SE}$ & & 2.77 & 4.68 & 7.24 \\
\hline LSD value & & 4.39 & 4.26 & 6.22 \\
\hline Level of significance & & 0.01 & 0.01 & 0.01 \\
\hline $\mathrm{CV}(\%)$ & & 14.21 & 9.39 & 9.92 \\
\hline
\end{tabular}

Means followed by common letters are not significantly different

From the discussion, it is clear that host crops and their varieties had a great role on the food consumption of red pumpkin beetle. Among three crops and nine varieties sweet gourd and variety Local Misti Kumra had the highest effect on the highest food 
consumption of red pumpkin beetle. Bitter gourd and the variety BARI Karola-1 had the lowest role on the food consumption of RPB. Temperature had a profound effect on the food consumption as well as oviposition of RPB. It was also found that $30^{\circ} \mathrm{C}$ was found the optimum temperature for food consumption and oviposition for the beetle considering the selected cucurbits and their varieties.

\section{REFERENCES}

Alam, M. Z. 1969. Insect Pests of Vegetables and Their Control in East Pakistan. Agril. Inf. Serv., Dept. Agric., 3, R. K. Mission Road, Dhaka, 149 p.

Azim, M. I. I. 1966. Studies on the biology of red pumpkin beetle, Aulacophora foveicollis (Lucas) (Chrysomelidae: Coleoptera) in East Pakistan. M. Sc. Thesis. Department of Entomology, Bangladesh Agricultural University, Mymensingh, $95 \mathrm{p}$.

Begum, L. A. A. 2002. Host preference of fruit fly and red pumpkin beetle to different cucurbit vegetables grown in summer. M.S. Thesis. Department of Entomology. BSMRAU, Gazipur, Bangladesh. 65 p.

Butani, D. K. and Jotwani, M. G. 1984. Insects in vegetables. Periodical Expert Book Agency. VivekVihar, Delhi (India). pp. 69-79.

Chaudry, Z. A. and Alikhan, M. A. 1990. Effects of temperature and relative humidity on the development and the fecundity of the red pumpkin beetle, Aulacophora foveicollis (Lucas) (Chrysomelidae: Coleoptera). Indian J. Entomol., 52(2): 274-278.

CRDS, 2010. Pest risk analysis of citrus and cucurbits of Bangladesh and listing quarantine pests. Centre for Resources Development Studies, Dhaka, Bangladesh. pp. 1-140.

Das, S., Uddin, M. M., Shahjahan, M. and Rahman, M. M. 2012. Effect of temperature on the behaviour of epilachna beetle (Epilachna dodecastigma Wied) among different brinjal varieties. J. Environ. Sci. $\mathcal{E}$ Natural Resources, 5(1): 167-172.

Dhillon, M. K., Naresh, J. S., Singh, R. and Sharma, N. K. 2005. Evaluation of bitter gourd (Momordica charantia L.) genotypes for resistance to melon fruit fly (Bactrocera cucurbitae). Indian J. Pl. Prot., 33(1): 55-59.

Doharey, K. L. 1983. Bionomics of red pumpkin beetle, Aulacophora foveicollis (Lucas) on some fruits. Indian J. Entomol., 45: 406-413.

Gupta, D. and Verma, A. K. 1992. Population fluctuations of the grubs of red pumpkin beetle, Aulacophora foveicollis (Lucas) infesting cucurbitaceous crops. Adv. Pl. Sci., 5: 518-523.

Hasan, M. K., Uddin, M. M. and Haque, M. A. 2012. Host suitability of red pumpkin beetle, Aulacophora foveicollis (Lucas) among different cucurbitaceous hosts. IRJALS. 1(4): 91-100.

Narayanan, E. S. and Batra, H. N. 1960. Red pumpkin beetle and their control. Indian Council of Agricultural Research, New Delhi, India. 2: 1-68.

Rajak, D. C. 2001. Host range and food preference of the red pumpkin beetle, Aulacophora foveicollis (Lucas) (Chrysomelidae: Coleoptera). Agril. Sci. Digest., 21(3): 179-181. 